\title{
Leishmaniasis and glycosaminoglycans: a future therapeutic strategy?
}

\author{
Débora Almeida Merida-de-Barros ${ }^{1,2}$, Suzana Passos Chaves ${ }^{1}$, Celso Luis Ribeiro Belmiro ${ }^{1}$ \\ and João Luiz Mendes Wanderley ${ }^{1,2^{*}}$
}

\begin{abstract}
Leishmania spp. depend on effective macrophage infection to establish and develop in mammalian hosts. Both metacyclic promastigotes and amastigotes are able to infect host cells, and thus they rely on several ligands that, when recognized by macrophage receptors, mediate parasite uptake. During macrophage primary infection with metacyclic forms from the insect vector and during amastigote dissemination via macrophage rupture, both infective stages have to cope with the host extracellular microenvironment, including extracellular matrix molecules.

Glycosaminoglycans are abundant in the extracellular matrix and many of these molecules are able to interact with the parasite and the host cell, mediating positive and negative effects for the infection, depending on their structure and/or location. In addition, glycosaminoglycans are present at the surface of macrophages as proteoglycans, playing important roles for parasite recognition and uptake. In this review, we discuss glycosaminoglycans in the context of Leishmania infection as well as the possible applications of the current knowledge regarding these molecules for the development of new therapeutic strategies to control parasite dissemination.
\end{abstract}

Keywords: Leishmania, Glycosaminoglycans, Macrophage, Receptors

\section{Background}

Innate immune cells express pattern recognition receptors (PRRs) on their surface, and they recognize pathogen-associated molecular patterns (PAMPs). Important examples of such receptors are dectin receptors, complement receptors (CR), mannose receptors (MR), scavenger receptors and Toll-like receptors (TLR). Several pathogens use these receptors as a route for cellular infection including protozoan parasites of the genus Leishmania. These parasites are the causative agents of leishmaniasis, a vector-transmitted disease endemic in several countries, especially in tropical and subtropical regions [1].

Leishmania parasites have as their main target cell the macrophage, a phagocytic cell that richly expresses PRRs. Infective forms of promastigotes and amastigotes of Leishmania use phagocytic PRRs as a way to interact with and infect host macrophages [2]. In addition, this interaction is

\footnotetext{
* Correspondence: Imwjoao@macae.ufrj.br

${ }^{1}$ Laboratório de Imunoparasitologia, Unidade Integrada de Pesquisa em

Produtos Bioativos e Biociências, Campus UFRJ-Macaé, Universidade Federal do Rio de Janeiro, Rio de Janeiro, Brazil

${ }^{2}$ Programa de Pós Graduação em Produtos Bioativos e Biociências, Campus UFRJ-Macaé, Universidade Federal do Rio de Janeiro, Rio de Janeiro, Brazil
}

capable of differentially activate PRRs to modulate and evade the immune response [3]. On its surface, Leishmania parasites express molecules that promote their binding to macrophages. One of them, glycoprotein 63 (gp63), is responsible for cleaving the $\mathrm{C} 3 \mathrm{~b}$ complement protein in iC3b [4], which opsonizes and binds the promastigote to the complement receptor 1 (CR1) [5]. Gp63 can also directly bind to fibronectin receptors [6]. Another surface molecule that induces Leishmania phagocytosis is the lipophosphoglycan (LPG), which binds to mannose receptors in macrophages [7] and complement receptor 3 (CR3) [8]. In Leishmania infantum chagasi, non-virulent promastigotes have been reported to bind to CR3 and mannose receptor, whereas metacyclic forms bind primarily to CR3. The entry via CR3 promotes a delay in phagolysosomal fusion, promoting parasitic survival [2]. Regarding amastigotes, an important route of entry into the cell is through IgG opsonization via Fcy receptors [9] and through the exposure of phosphatidylserine (PS). Amastigote forms expose PS on their surface, mimicking apoptotic bodies, which leads to the release of TGF- $\beta$ by infected macrophages leading to a decrease in nitric oxide (NO) production [10]. Additionally, macrophage recognition of

(c) The Author(s). 2018 Open Access This article is distributed under the terms of the Creative Commons Attribution 4.0 International License (http://creativecommons.org/licenses/by/4.0/), which permits unrestricted use, distribution, and 
PS molecules induces tethered and bystander macropinocytic uptake of particles, which leads to amastigote internalization and infection establishment [10]. This mechanism is also important for metacyclic primary infection, but in this case, the parasites are actually suffering apoptosis, and this is important for phagocyte deactivation and the establishment of live, PS-negative metacyclic promastigotes, including in natural transmission [11].

There are also PRRs that Leishmania uses to modulate infection and/or evade the immune response, for example, Toll-like receptors [3]. Recently, Dos Santos et al. [12] demonstrated that the activation of human nucleotide-binding oligomerization domain containing 2 (NOD2)-like receptor (NLR) is important for the intracellular recognition and control of New World Leishmania spp., etiological agents of American tegumentary teishmaniasis. In addition to receptor activation, Leishmania has several mechanisms of immune response evasion. The transformation into the intracellular amastigote is a form of resistance to the immune response, since it is more resistant to the low $\mathrm{pH}$ of the parasitophorous vacuole, oxygen peroxide, nitric oxide and lysosomal enzymes. Gp63 and LPG mediate mechanisms already described, where both have complementary actions. After endocytosis, LPG delays the fusion of the phagosome with the lysosome and gp63 inhibits the activation of lysosomal enzymes, favoring the survival of Leishmania [13-15]. In addition, both molecules are capable to inhibit the oxidative burst [16, 17]. Leishmania infection leads to the interruption of several macrophage effector mechanisms, such as reduction of the microbicidal capacity by inactivation of the enzyme inducible nitric oxide synthase (iNOS) and oxidative system [18]. PGE2 and TGF- $\beta$ release block the function of macrophages [19]. The C3b cleavage in $\mathrm{iC} 3 \mathrm{~b}$ by Factor I, induced by gp63, helps in the avoidance of the effector actions of the complement system [19]. There are also evasion mechanisms of the adaptive immunity, such as induction of decreased expression of MHC class II molecules [20], inhibition of antigen loading and processing, and induction of Th2 response by Lack antigen.

It has also been shown that L. amazonensis promastigotes possess ecto-ATPases, which have been related as virulence factors of the parasite. During tissue injury, release of ATP to the extracellular medium occurs, inducing the production of inflammatory cytokines such as IL-12 and TNF- $\alpha$. These ecto-ATPases degrade ATP in $\mathrm{ADP}$ and later in AMP. This is converted into adenosine by $\mathrm{CD} 73$, which has an anti-inflammatory role in the infection by decreasing the production of inflammatory cytokines and stimulating IL-10 release [21, 22].

Although several different receptors and ligands play major roles in Leishmania/macrophage interactions, usually the infection is not completely abrogated by the blockage of one or some of these mechanisms of infection. This indicates that there are other players that have not been fully identified yet, influencing the infective process. In studies of parasite/host relationship, it has been demonstrated that proteoglycans and glycosaminoglycans are also involved in modulating macrophage infection by the promastigotes and amastigotes of Leishmania spp. as well as modulating the infected host cell itself [23-25].

\section{Proteoglycans}

Proteoglycans (PGs) are a heterogeneous group of glycoconjugates widely distributed in animal tissues, from the earliest to the most recent phyla [26]. All PGs identified are composed of glycosaminoglycan chains (GAGs) covalently attached to a protein skeleton [27, 28]. These macromolecules present a great structural diversity due to the many possibilities of polysaccharide and protein binding, different proteins involved, and GAGs' structural diversity. This characteristic contributes to the involvement of PGs in a wide variety of biological functions $[29,30]$. The PG superfamily contains more than thirty known molecules. They act as tissue organizers, influence the growth and maturation of specialized tissue cells, function as biological filters, modulate the activity of growth factors, modulate inflammatory responses, regulate collagen fibrillogenesis, affect cell invasion and growth and are involved in host-parasite relationships [28, 31-33].

With the exception of hyaluronic acid (HA) all other GAGs are synthesized as PGs. This process begins in the rough endoplasmic reticulum with the addition of a xylose residue to the amino acids serine or threonine in the protein skeleton [30,34]. Then, specific transferases of the cis and median portions of the Golgi complex add two units of galactose and one of glucuronic acid, forming the binding tetrasaccharide, common to most GAGs $[35,36]$. In the case of keratan sulfate (KS), GAG chains may be attached to the protein via $\mathrm{O}$ - or $\mathrm{N}$-glycosidic $\mathrm{N}$-acetyl-galactosamine (GalNac) or $\mathrm{N}$-acetyl-glucosamine (GlcNAc) to the serine or asparagine/threonine residues, respectively. The binding of the tetrasaccharide functions as an initiator sequence for the polymerization of the GAG chain in the biosynthesis of chondroitin sulfate, dermatan sulfate, heparan sulfate and heparin $[35,36]$. Chain elongation occurs through the alternating addition of hexosamine and hexuronic acid by membrane-specific glycosyltransferases. After polymerization, the GAG chain is modified by the action of epimerases, that determines which glucuronic acid units will be transformed into iduronic acid, and by sulfotransferases, which determine the degree of sulfation of the final structure that is often transported to the cell surface or extracellular matrix [27, 31-33]. 


\section{Classification of proteoglycans}

PGs can be classified according to the following parameters: type of GAG, cell location and homology of their protein skeleton [32]. The first parameter is outdated, since the same type of PG can present different types of GAG chains. Here we briefly describe the different families of PGs classifying them according their cellular or extracellular location.

\section{Extracellular proteoglycans}

Versican, aggrecan, neurocan and brevican are PGs secreted and deposited in the extracellular matrix and play a very important role filling intercellular spaces and keeping cells and tissues together. These PGs interact with hyaluronic acid (HA) and lectins, also known as hyalectans [32]. The common characteristic is the presence of three well-defined domains: the $\mathrm{N}$-terminal domain, which binds hyaluronic acid; the repetitive central domain, which contains GAG chains of the type chondroitin sulfate (CS); and KS, and the C-terminal domain, which binds to lectins [37]. These features allow these PGs to function as molecular bridges between matrix components and the cell surface [28, 31-34].

Small leucine-rich PGs are typically characterized by having core proteins with leucine rich sequences. The protein skeleton of these PGs has three distinct regions: an amino-terminal containing GAGs or L-tyrosine sulfate, a central domain containing leucine-rich repeating sequences bounded by residues of L-cysteine and a carboxy-terminal region that is not well characterized [28]. To date, at least nine families have been characterized, based on their genomic and protein organization. As examples we have decorin and biglycan, both PGs containing chondroitin sulfate and/or dermatan sulfate chains [31, 33].

Facultative PGs do not have structural characteristics that include them as members of the families previously described. In addition, they can be found as an exclusive constituent of proteins expressed in a GAG-free chain form. Collagen 2 (IX), testican and apican are examples of PGs of this group [31-33].

Basement membrane PGs are extracellular PGs found in the basal lamina. They form a thin, flexible layer of specialized extracellular matrix located under all cell layers [32]. In the pulmonary alveoli and renal glomeruli, the basal membrane functions as a selective filter but it can have different functions in other organs [38]. Base membrane PGs present a variable composition among the tissues, but the presence of collagen type IV, laminin and at least one type of PGs from other families is common [31-33].

\section{Proteoglycans of cytoplasmic granules}

PGs can be found inside cytoplasmic granules, such as serglycin which is a constituent of mast cells, neutrophils and endothelial cells granules. These PGs are important for the binding and storage of proteases within the secretory cytoplasmic granules. They are involved with inflammatory and immune responses. Their nomenclature depends on the protein chain and the number of repetitive sequences of L-serine-L-glycine [31-33].

\section{Cell surface proteoglycans}

All processes of cell communication and interaction, both with other cells or extracellular matrix components, can be attributed, at least in part, to the surface PGs. Most animal cells have on their surface PGs that may contain mostly heparan sulfate chains, but also chondroitin sulfate and dermatan sulfate [39]. Association with cell surfaces can occur in several ways: directly through non-covalent interactions between the GAG chain or the protein chain with binding sites present on the cell membrane; by intercalation of the PG protein chain in the membrane; by the anchoring the PG to the membrane via glycosylphosphatidylinositol (GPI) lipid anchors [40,41] or indirectly involving other matrix macromolecules such as laminin or fibronectin, which are capable of binding PG and integrins [31-33, 42]. Glypicans, are GPI anchored heparan sulfate-based PGs which has been identified in several cell types [37, 39]. Syndecans are PGs inserted into the plasma membrane through a hydrophobic domain, which are mainly found in epithelial cells. Syndecans 1 and 3 present hybrid chondroitin sulfate and heparan sulfate chains whereas syndecans 2 and 4 contain only heparan sulfate. Among the functions attributed to this family of PGs, most are related to the ability to recognize extracellular molecules since syndecans bind to various molecules, such as collagens type I to V, fibronectin, thrombospondin, tenascin and laminin [39]. In addition, they bind to molecules that are associated with cell growth such as bFGF, VEGF, HGF and some cytokines [34, 43-47]. Other PGs, also integral membrane molecules are: CD44, betaglycan (TGF-growth factor receptor), transferrin receptor, invariant chain PGs, integrin 51 and thrombomodulin [31-33, 42, 48].

\section{Glycosaminoglycans}

Glycosaminoglycans (GAGs) are a complex family of linear polysaccharides, consisting of repeating disaccharide units of hexosamine ( $N$-acetyl-glucosamine or $\mathrm{N}$-acetyl-galactosamine) attached through $\mathrm{O}$-glycosidic linkage to a hexuronic acid (glucuronic acid or iduronic acid) or to galactose [37]. Hexuronic acid residues may exhibit $O$-sulfation at carbon 2 , while galactose may be 
6-O-sulfated. However, hexosamine may exhibit $\mathrm{O}$-sulfation at carbons 4 and/or 6 and also $N$-sulfation [37]. The structure of different GAGs is depicted in Fig. 1. Sulfate groups, together with the carboxylic acids of uronic acids, attribute to these molecules a high density of negative charges. In recent years, studies of polysaccharides, especially those related to their biological activities, have been attracting increasing interest. The applicability of this group of molecules in different fields, such as health, industry and agriculture, is due to structural characteristics, often species-specific, associated with heterogeneity in size, monosaccharide composition and presence of different negatively charged groups, such as sulfates and carboxylates [42, 49]. Table 1 summarizes studies on different GAGs and their main functions [50-73].

\section{Hyaluronic acid (HA)}

HA has a simple structural composition, being fundamental in the structural organization of the extracellular matrix. Its disaccharide units, composed of $\mathrm{N}$-acetylglucosamine and glucuronic acid are not sulfated, therefore the anionic properties of HA are given by its carboxyl groups [37]. Unlike other GAGs, HA is not synthesized covalently linked to the protein chain, and is therefore classified simply as GAG [74]. They form high molecular weight polymers ranging from 106 to $107 \mathrm{kDa}$, being important components of the extracellular matrix, where they interact non-covalently with the PGs. They are particularly abundant in the connective tissue, dermis, smooth muscle, lung, lamina propria of the mucosa and adventitious layer that surrounds the blood vessels [42, 49, 74].

\section{Chondroitin sulfate (CS)/dermatan sulfate (DS)}

CS and DS are considered as GAGs belonging to the same family because they present as disaccharide units an $\mathrm{N}$-acetylgalactosamine linked to a glucuronic acid in the case of CS or to an iduronic acid in the DS case. CS can have the sulfated $\mathrm{N}$-acetylgalactosamine at the 4- or 6- positions, forming the chondroitin 4- or 6-sulfates, respectively. DS is an isomeric form of chondrocyte 4-sulfate where, in most of its disaccharide units, we find

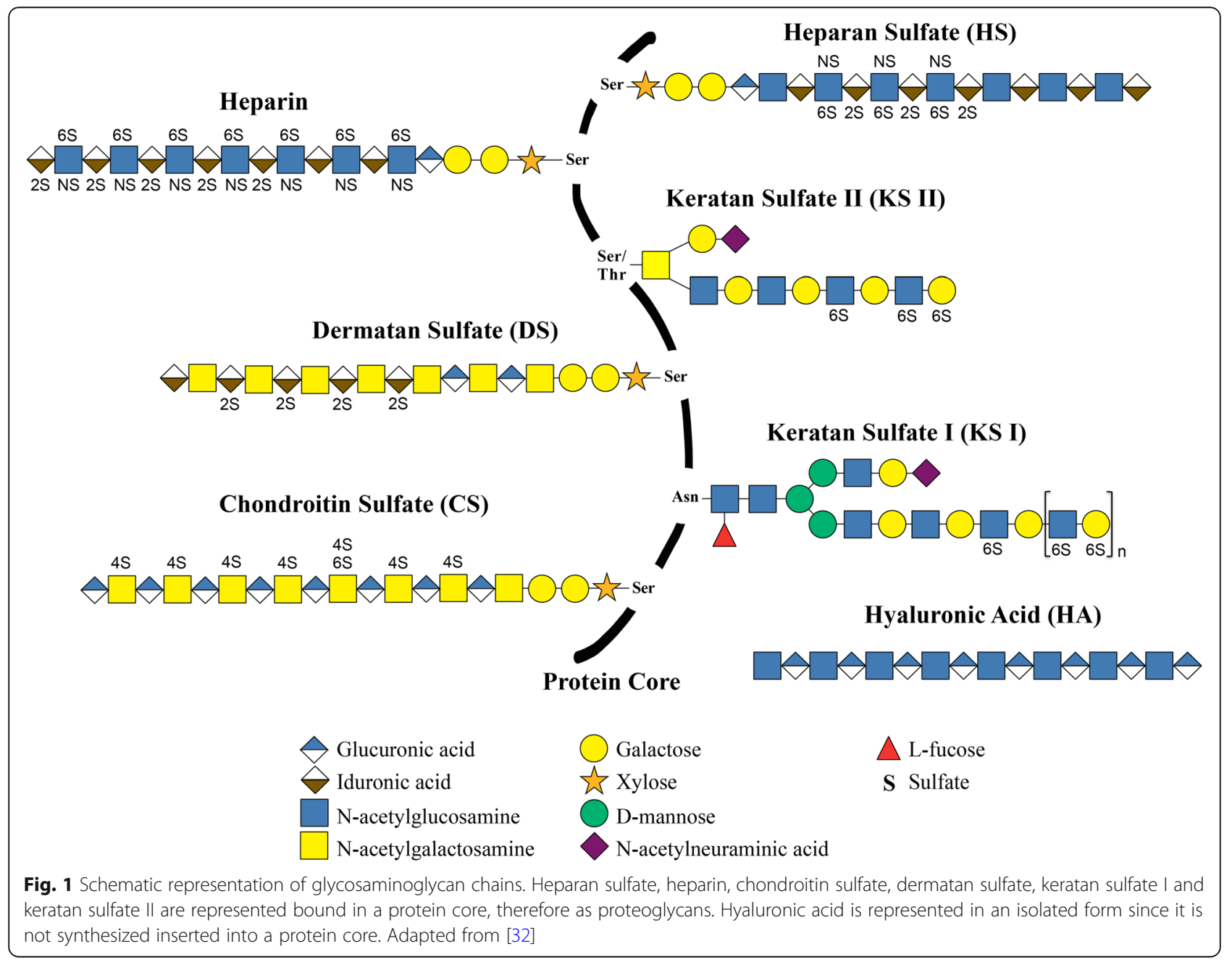


Table 1 References regarding the physiological functions of glycosaminoglycans in animal cells and tissues

\begin{tabular}{|c|c|c|c|c|c|c|}
\hline $\begin{array}{l}\text { Physiological } \\
\text { function }\end{array}$ & Heparin & Heparan sulfate & Chondroitin sulfate & Dermatan sulfate & Hyaluronic acid & Keratan sulfate \\
\hline $\begin{array}{l}\text { Cell-cell/cell- } \\
\text { matrix } \\
\text { interactions }\end{array}$ & - & Thakar et al. [54] & Milstone et al. [58] & Lewandowska et al. [63] & Underhill et al. [67] & $\begin{array}{l}\text { Funderburgh } \\
\text { et al. [72] }\end{array}$ \\
\hline $\begin{array}{l}\text { Immune } \\
\text { modulation }\end{array}$ & $\begin{array}{l}\text { Almeida et al. [50] } \\
\text { Borsig et al. [51] }\end{array}$ & $\begin{array}{l}\text { Almeida et al. [50]; } \\
\text { Thakar et al. [54] }\end{array}$ & Borsig et al. [51] & Nadafi et al. [64] & $\begin{array}{l}\text { Horton et al. [68]; } \\
\text { Termeer et al. [69] }\end{array}$ & Leroux et al. [73] \\
\hline $\begin{array}{l}\text { Host-pathogen } \\
\text { interactions }\end{array}$ & Angeletti et al. [52] & $\begin{array}{l}\text { Takemae et al. [55]; } \\
\text { Ndonwi et al. [56] }\end{array}$ & $\begin{array}{l}\text { Rogerson et al. [59]; } \\
\text { Ayres Pereira et al. [60] }\end{array}$ & $\begin{array}{l}\text { Ndonwi et al. [56]; } \\
\text { Fortune et al. [65] }\end{array}$ & $\begin{array}{l}\text { Beeson et al. [70] } \\
\text { Skinsnes et al. [71] }\end{array}$ & - \\
\hline $\begin{array}{l}\text { Anticoagulant } \\
\text { activities }\end{array}$ & McLean et al. [53] & Shworak et al. [57] & $\begin{array}{l}\text { Mourão et al. [61]; } \\
\text { Glauser et al. [62] }\end{array}$ & Ofosu et al. [66] & - & - \\
\hline
\end{tabular}

iduronic acid instead of glucuronic acid. The sulfation pattern of these GAGs may still be very complex because, depending on the type of tissue or organism, the disaccharide units may exhibit extra sulfation giving rise to the disulfated disaccharide units [37, 75]. In the case of CS, the $\mathrm{N}$-acetylgalactosamine can be both sulfated at its 4- and 6- positions whereas in DS the extra sulfation can be at the 2-position of iduronic acid [42, 49].

\section{Keratan sulfate (KS)}

KS has disaccharide units composed of $\mathrm{N}$-acetylglucosamine, which can be sulfated at the position 6 , and galactose instead of a hexuronic acid. In addition to this particularity, KS chains can be either $O$ - or $N$-linked to the PG chain, having as the point of attachment a serine or asparagine/threonine residues, respectively. We can cite two types of Keratan sulfate according to their binding to protein core, KS type I and KS type II [37, 42, 49, 76].

\section{Heparin (Hep) and heparan sulfate (HS)}

Both Hep and HS present the glucosamine amino sugar, which may be $O$-sulfated at position 6 in the case of HS and preferably $\mathrm{N}$-sulfated at the 2-position and $\mathrm{O}$-sulfated at position 6 , in the case of heparin. Regarding the composition of hexuronic acid, it is verified that heparin contains mainly iduronic acid, with varying amounts of $\mathrm{O}$-sulfation at position 2, whereas HS contains more glucuronic acid, usually not sulfated. However, it is important to note that there are differences between these two molecules. The degree of sulfation is one of the main factors used to differentiate these two molecules. Based on this information, it is possible to say that heparin is composed mainly of disaccharide units of type $\operatorname{IdoA}(2 S)$ GlcNS(6S), while HS contains a small proportion of this disaccharide, being mainly characterized by having a greater variety in composition of their disaccharide units. However, these are less sulfated than those present in heparin. It is important to note that heparin can be isolated from different animal tissues, including vertebrates or invertebrates $[26,77]$. In mammals, it is synthesized and stored in cytoplasmic granules of mast cells, being released as free non-protein bound molecules after activation and degranulation of mast cells, in events associated with the immune system. HS is synthesized and expressed on the cell surface of a wide variety of cell types, and can be secreted either in the form of free GAGs or PGs [34, 48, 49, 78, 79].

\section{Occurrence and biological activities of glycosaminoglycans}

The presence of GAGs in vertebrate and invertebrate animal cells and tissues is already well described in the literature [31, 33, 80]. Research has shown that these GAGs are involved in several biological functions such as cell-cell and cell-to-matrix interactions [33, 81], immobilization of cytokines and chemokines, cell adhesion and in the immune response of different types of organisms [81-84]. These molecules also play a role in host-parasite interactions [85], in addition to the known remarkable anticoagulant activities of these molecules [80]. Among these biological activities we will focus on host-parasite interaction. In several cases, the ability of pathogenic microorganisms to bind to the surface of host cells, define the course of infection. In this sense, a wide variety of bacteria, viruses and parasites, including intracellular and extracellular ones, was identified, which require interaction with host cell heparan sulfate molecules via a variety of $\mathrm{HS}$ receptors to establish their infections [85-87].

In recent years, studies of GAGs, especially those related to their biological activities, have been attracting significant interest. The applicability of this group of molecules in distinct fields, such as health sciences, is due to structural characteristics, often species-specific, associated with size heterogeneity, monosaccharide composition and the presence of different negatively charged groups such as sulfates and carboxylic acids [88, 89]. In recent decades, GAG analogues have been identified, especially in marine organisms such as the ascidian, sea cucumbers, mussels, crustaceans and mollusks [29, 90]. Studies have shown that these analogues have many biological activities [49]. GAGs were isolated and characterized as mussel heparin 
analogs with significant anticoagulant activity [90]. A heparin analogous to the mammalian heparin was isolated and characterized from the ascidian Styela plicata, presenting less anticoagulant activity, although with anti-inflammatory activity $[49,89]$. In addition, the identification of a heparan sulfate-like molecule from the mollusk Nodipecten nodosus, revealed a molecule with potent anticoagulant activity, capable of inhibiting thrombus formation in ischemic diseases [91] A dermatan sulfate with a high degree of sulfation was also identified and characterized in Styela plicata and Phallusia nigra ascidian, with specific anticoagulant activities. In addition, the development of ascidian neural cells has also been associated with these GAGs [92, 93]. Furthermore, chondroitin sulfate analogues from sea cucumbers Ludwigothurea grisea, have antithrombotic activity, in addition to inhibiting the binding of P-selectin to leukocytes $[94,95]$.

An important aspect to consider when proposing the therapeutic use of natural compounds of animal origin is the risk of contamination with pathogens. For example, the association of prion mammalian proteins with transmissible spongiform encephalopathy has recently restricted the use of bovine heparin in Europe, Japan and the USA [96]. Currently, commercial heparin is obtained exclusively from swine tissues and the risk of contamination is still present. Therefore, when considering therapeutic strategies using mammalian GAGs, it is important to take account their side effects and the possibility of contamination with pathogens. In this context, the search for alternative analog GAG compounds obtained from non-mammalian animal sources and having similar biological activities, becomes extremely relevant.

\section{Glycosaminoglycans and Leishmania infection Glycoconjugates and Leishmania infection}

Natural Leishmania infection involves several differentiation steps, culminating with the development of infective metacyclic promastigotes that migrate to the sand fly anterior midgut $[97,98]$. The parasites remain there embedded in a filamentous proteophosphoglycan matrix called promastigote secretory gel (PSG) that jams the food flow blocking a new blood intake. This is fundamental for the transmission, since the vector needs to regurgitate the content of the gut to take a new blood meal, delivering parasites, saliva and PSG intradermally to the mammalian host [99-101]. Actually, Leishmania parasites are prone to produce phosphoglycan-containing molecules with variably phosphodisaccharide repetitions, predominantly (Gal-Man- $\mathrm{PO}_{4}$ ). These molecules include the lipophosphoglycan (LPG), PSG and proteophosphoglycans [102]. Whereas LPG is a membrane-anchored molecule that functions as a virulence factor, being recognized by complement receptors in phagocytic cells [8], PSG is secreted and seems to be involved in the modulation of the microenvironment at very early stages post transmission. PSG is actively expelled by infected sand flies during the blood meal and its presence exacerbates cutaneous infection in both resistant and susceptible mice strains $[100,101]$. This effect seems to be due to the chemoattraction of macrophages and neutrophils to the lesion site, providing host cells for the establishment of the infection [103]. In addition, PSG is able to reduce the leishmanicidal activity of M1 macrophages, through induction of arginase I expression in these cells and thus diminishing nitric oxide production [103]. Combined, the consequences of PSG promote the development of chronic Leishmania infections, even in resistant mice strains, in a LPG-independent and proteophosphoglycan-dependent manner [100]. This mechanism operates in a large variety of Leishmania species such as L. mexicana, several strains of L. major, L. amazonensis, L. braziliensis, L. aethiopica, L. infantum and L. donovani [100]. Although the effects of PSG seem to be as important as the sand fly saliva to enhance and modulate infection, the receptors involved on its recognition in both parasite and host cells are largely unknown.

Leishmania parasites and other protozoan parasites possess immunogenic glycoconjugates at their surface. Most of these molecules are glycosylphosphatidylinositol (GPI) anchored molecules, similar to glypicans, although they are not considered GAGs due to differences in structure and synthesis [104]. These molecules are collectively known as glycoinositolphospholipds (GIPLs) and have a basic structure of Man $1-4$ GlcN linked to an alkyl-acylglycerol through a phosphatidylinositol residue [105]. Polymorphic and biochemical variations led to the classification of these molecules in three groups: Type I, II and III GIPLs. Type I GIPLs are composed of an $\alpha 1,6-$ mannose residue linked to Man $\alpha 1-4 \mathrm{GlcN}$ motif. This type of GIPL is observed in Old World Leishmania species such as L. donovani, L. aethiopica and L. tropica [106]. Type II GIPL presents an $\alpha 1,3$-mannose residue linked to Mano1-4GlcN motif and is structurally associated to LPG molecules. It is widely observed in Old World and New World Leishmania species such as L. major, L. panamensis and L. mexicana [107-109]. Type III GIPLs are heterogeneous molecules with mixed structural characteristics of type I, type II and unclassified GIPLs [109]. GIPLs are highly immunogenic and leishmaniasis patients are usually positive for specific antibodies anti-GIPL, although there is no described correlation with protection. This is particularly demonstrated in L. major-infected patients [104], and this characteristic is being explored in a vaccine-based therapeutic strategy based on $\alpha$ Gal-containing neoglycoproteins [110]. These molecules act as virulence factors since they seem to negatively regulate macrophage activity as observed in $L$. major, $L$. braziliensis and L. infantum infections [111]. 
Once transmitted by an infected sand fly, parasites have to cope with the host microenvironment, especially the extracellular environment, which is not their natural residence. Flagellate promastigotes and amastigotes, the infective stages of the parasite, are deposited in the lesion site extracellular matrix, respectively during the blood meal and macrophage rupture. During these events, parasites interact with extracellular matrix (ECM) proteins, sugars and growth factors [112-114] and these interactions are important for infection establishment. In addition, macrophages and other host cells interact with ECM contents and these interactions have positive and negative effects for the infection [115]. In this context, GAGs are interesting molecules because they are able to interact with parasites when encountered in ECM and at the surface of host cells modulating parasite growth and lesion development [115]. Parasite interaction with surface PGs or exogenous GAGs is depicted in Fig. 2 and is discussed in this review. GAGs' interactions with parasites were first evaluated by treating $L$. donovani promastigotes with hyaluronidase or hyaluronic acid (HA) to observe in vitro growth, viability and motility. It was observed that hyaluronic acid treatment induced marked reduction of promastigote mobility, without evidence of toxicity, suggesting that the presence of this molecule can facilitate parasite uptake by host cells. However, at that point there was no evidence of direct binding of HA to the surface of promastigotes [116]. It has been shown that heparin is capable of modulating protein kinase activity, both positively and negatively [25]. Since heparin can be present in the lesion site and be produced by resident leukocytes involved in inflammatory responses such as mast cells, its effect on promastigotes of $L$. donovani was observed. Heparin is able to inhibit protein kinase activity of promastigotes, decreasing the amount of phosphorylated proteins. This activity is dependent on heparin-binding to promastigotes via specific receptors, since dermatan sulfate (DS), chondroitin sulfate (CS) or HA were not capable of competing with heparin for its receptor [25]. Direct effects for parasite infectivity of protein kinase inhibition due to heparin-binding was not observed. The heparin receptor of the parasite is a surface protein, directed to the plasma membrane from an intracellular stored pool, mainly expressed at the flagellum and flagellar pocket [23]. Its specificity depends on the size of the oligosaccharide chain, with at least 8-16 monosaccharide repetitions being necessary for proper binding. The level of sulfation is also important for promastigote binding to GAGs. Complete desulfation of octa-, dodeca- and hexadecasaccharides almost completely abrogates promastigote binding to these GAGs. On the other hand, oversulfation of DS is able to promote promastigote binding to this GAG [23]. In a more detailed work, Fatoux-Ardore et al. [113] evaluated 24 different strains from six different

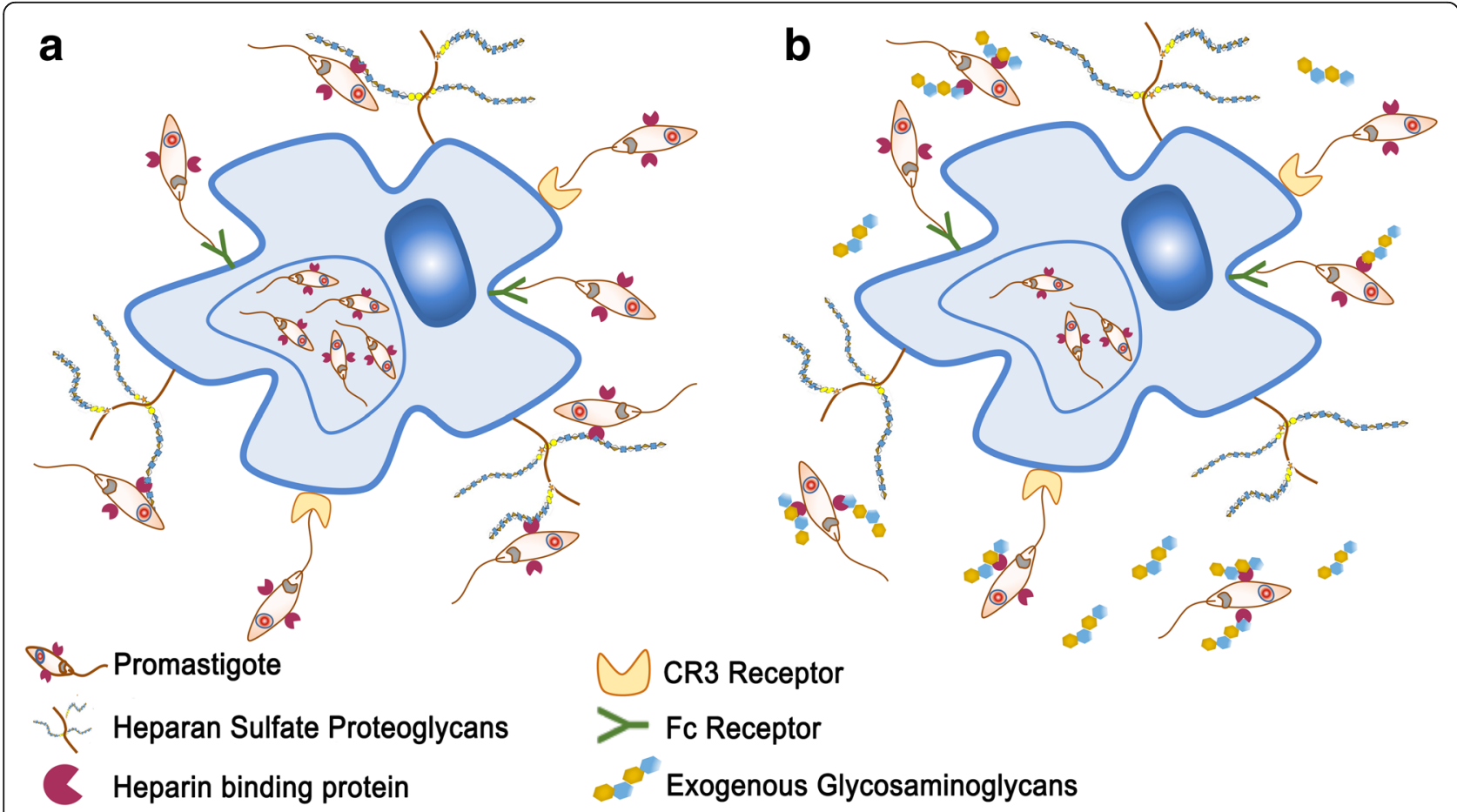

Fig. 2 Glycosaminoglycans as a therapeutic strategy. a Heparin-binding protein from Leishmania spp. recognizes and binds to glycosaminoglycans (GAGs) in the surface of macrophages. This recognition is important for parasite binding to and infection of macrophages. $\mathbf{b}$ Exogenous GAGs may interfere with this interaction, decreasing macrophage infection and parasite dissemination/survival 
species of Leishmania for their interactions with ECM GAGs and proteins. They analyzed Old and New World species that cause cutaneous, mucocutaneous or visceral leishmaniasis. The capacity of promastigotes to bind to GAGs was assessed by surface plasmon resonance imaging and it was observed that most strains tested are capable to bind to high molecular weight heparin, heparan sulfate, 2-O, 6-O and $\mathrm{N}$-desulfated heparin, whereas less than $12 \%$ of the strains tested were capable to bind to dermatan and chondroitin sulfate. Binding to low and high MW hyaluronan was observed by most species tested. However, few parasite strains were able to bind to these molecules, with the exception of $L$. donovani promastigotes. It is interesting to observe that several strains that were able to bind to heparin do not bind to HS [113]. This can be due to the level of sulfation observed in these molecules and is relevant for possible correlations between heparin-binding ability of promastigotes and the HS proteoglycan-dependent macrophage infections. One possible role for GAGs interactions with Leishmania parasites is that these molecules are able to induce the activity of cysteine proteinases. Parasites in the ECM prior to host cell engulfment also interact with ECM proteins and can co-opt some of these molecules for their growth, survival and infection. GAGs can form ternary complexes with cruzipain and cathepsin $\mathrm{K}$ and $\mathrm{B}$, increasing kininogen and collagen proteolytic cleavage [117-120]. GP63, which is the main surface protease of Leishmania parasites, is also important for ECM cleavage [112]. GAGs also modulate cysteine proteinase B (CPB), an enzyme important for L. mexicana infection, nutrition and immune system escape [121]. Heparan, heparin and heparin-like GAGs were able to modulate CPB activity. This modulation can be positive and negative since heparin at concentrations below $2 \mathrm{mM}$ can potentiate the production of mature $\mathrm{CPB}$ whereas at concentrations above $20 \mathrm{mM}$ these molecules inhibit this conversion [121]. It is possible to conclude that the interaction with host cells and the lower concentration of GAGs associated with proteoglycans could induce CPB activation, contributing to the infectious process, while the higher concentrations of free chains of GAGs at the ECM at the inflammatory site of the infection could contribute to $\mathrm{CPB}$ inhibition and parasite control. ECM GAGs can also have positive effects for the infection, stimulating parasite survival. Intracellular amastigote forms of $L$. major depend on the uptake and degradation of ECMs GAGs by macrophages [115]. $N$-acetylglucosamine acetyltransferase (GNAT) deficient $L$. major amastigotes are not capable to proliferate inside in vitro cultured macrophages, even in the presence of $\mathrm{N}$-acetylglucosamine (GlcNAc). Amastigote proliferation is only efficient in vivo or in vitro when macrophages are cultured in media enriched with HA which is a desulfated GlcNAc-rich GAG abundant in the
ECM [115]. It was observed that HA is engulfed by macrophages, transported to the parasitophorous vacuoles and degraded. The GlcNAc residues are used by the parasite to resume production of glycoconjugates, including plasma membrane glycolipids and proteoglycans including lipophosphoglycan and GP63, important virulence factors [115].

\section{Modulation of Leishmania/macrophage interaction by glycosaminoglycans}

Direct binding of Leishmania parasites with cell surface proteoglycans has been shown to play a role for the infection of L. amazonensis, L. major, L. donovani, L. infantum chagasi, L. mexicana and L. brasiliensis [24, 122-125]. Most of the reports suggest a role for the infection of mammalian host cells, although there is some evidence indicating that receptors at the surface of $L$. braziliensis are able to recognize plasma membrane HS in Lulo cells, which is a cell line derived from Lutzomyia longipalpis gut cells [126]. This interaction could cooperate with the lectin-dependent binding of promastigotes promoting adhesion to the sand fly gut.

Receptors of the parasite involved in the recognition of GAGs are collectively called heparin-binding proteins (HPB) although most of them are able to recognize several GAGs, especially highly sulfated heparin-like molecules such as heparan sulfate (HS). They were first enrolled as virulence factors for $L$. donovani parasites, mediating amastigote and promastigote macrophage infections [23-25]. Only stationary-phase promastigotes are able to express these proteins, which is consistent with the presence of infective promastigotes at this phase of the axenic culture $[23,24]$. Surprisingly, pre-incubating promastigotes with heparin enhanced macrophage infection suggesting that heparin could provide a bridge between the parasite HPB and macrophage heparin receptors [24].

Leishmania amazonensis amastigotes have a high affinity for heparin and especially for HS proteoglycans at the surface of host cells. Mammalian host cells treated with heparitinase lose their ability to bind to L. amazonensis amastigotes. Differently to what happens in $L$. donovani infection, addition of exogenous heparin blocked amastigote adherence to non-myeloid mammalian cells such as CHO, HEp-2 and NIH-3T3 cells. In addition, efficient inhibition of amastigote-to-macrophage binding was obtained by pre-treating the parasite prior to their addition to macrophage cultures [125]. However, HS efficiently inhibits $L$. amazonensis amastigote binding to macrophages. Amastigotes are incapable of binding to mutant $\mathrm{CHO}$ cells that do not produce GAGs or do not synthesize specifically $\mathrm{HS}$. $\mathrm{CHO}$ cells that express undersulfated HS are also less capable of binding to amastigote forms, even when these cells express similar amounts of sulfated proteoglycans due to overexpression 
of chondroitin sulfate [125]. Amastigotes of L. major express a similar HBP, being the receptor specific to HS or heparin-like GAGs [125]. This data is interesting because HS is more relevant for amastigote/macrophage interactions since this GAG is abundant at the membrane of macrophages. However, the effect of HS or heparin blocking macrophage infection is partial (ranging from 40-60\%), suggesting cooperation with additional mechanisms for macrophage infection [125]. It was demonstrated that proteins with heparin-affinity were expressed only at the flagellum and the flagellar pocket of $L$. donovani [23] but $L$. braziliensis promastigotes express HBP at the plasma membrane, although HBP is more abundant and have higher activity at the flagellar fraction of the parasite [123, 124]. Leishmania infantum chagasi promastigotes express HBP at the plasma membrane, flagellum and flagellar pocket. It seems that these proteins are also stored inside the parasite cell, since they could be detected on several intracellular compartments such as the nucleus, mitochondria and kinetoplast. Polyclonal anti-HBP antibodies were not able to block HBP-dependent infection in vitro [123, 124]. This may be due to secondary opsonization. The presence of heparin was able to decrease promastigote internalization by macrophages, but not adhesion [124]. This suggests that for $L$. infantum chagasi HBP may play a role as a phagocytic ligand.

\section{Glycosaminoglycan-based therapeutic strategies}

It is possible that HBP are canonical proteins involved in the invasion of host cells by protozoan parasites, particularly trypanosomatids. Trypanosoma cruzi, the etiological agent of Chagas disease expresses a HBP with affinity for HS and heparin. These proteins are expressed by trypomastigote and amastigote forms and are involved with cardiomyocyte infection $[127,128]$. It was observed that heparin and HS effectively inhibit cardiomyocyte infection, but not keratan sulfate, dermatan sulfate or $\mathrm{N}$-acetylated HS [128], demonstrating the specificity of the interaction, as well as the similarities to the HBP expressed by Leishmania parasites. Although several reports demonstrated the relevance of HBP-dependent parasite infection there is no evidence that this host-parasite interplay can be explored as a therapeutic target. HBP-dependent infection in vitro is successfully inhibited with HS, heparin and heparin-like molecules, which place these molecules as possible compounds capable to diminish parasite invasion and subsequent infection dissemination. Usually, the activity of GAGs as inhibitors of Leishmania infection depends on the number and type of saccharide units, sulfation of the molecule and protein interactions $[23,24,123,125]$. In addition, it is necessary to evaluate possible adverse effects of HBP natural competitors, such as heparin. The anticoagulant activity of heparin can be detrimental to the host even when administered locally, since it may cause parasite dissemination and extensive bleeding. HS, which has an overall decreased but existent ability to inhibit HBP [125], has other features to be considered, such as cost. One possible alternative is the heparin analogues or heparin-like exogenous molecules derived from non-mammalian sources (Fig. 2). Some of these molecules display less anti-coagulant activity but remain capable to interact with mammalian host cells, including modulating inflammatory response [89, 129]. These molecules could be used as antagonists of HBP, decreasing macrophage invasion and disease progression (Fig. 2). However, the ability of these molecules to bind to parasite HBP still needs to be determined.

\section{Conclusions}

Study of Leishmania/glycosaminoglycans/host cell interactions may be important to fully understand parasite infection and dissemination. The characteristics of glycosaminoglycans, especially their low toxicity and availability from non-mammalian sources, plus their promising effects in modulate in vitro Leishmania infections compared to the current treatment, make them a potential new therapeutic strategies to control tegumentary leishmaniasis.

\section{Abbreviations \\ ADP: adenosine diphosphate; AMP: adenosine monophosphate; \\ ATP: adenosine triphosphate; bFGF: basic fibroblast growth factor; CD: cluster of differentiation; $\mathrm{CHO}$ cells: Chinese hamster ovary cells; CPB: cysteine \\ proteinase $\mathrm{B}$; CR: complement receptor; CS: chondroitin sulfate; DS: dermatan sulfate; ECM: extracellular matrix; EGF: epidermal growth factor; \\ GAG: glycosaminoglycan; GalNac: N-acetyl-galactosamine; \\ GIPLs: glycoinositolphospholipds; GlcNAc: N-acetyl-glucosamine; GNAT: N- acetylglucosamine acetyltransferase; gp63: glycoprotein 63; \\ GPI: glycosylphosphatidylinositol; HA: hyaluronic acid; HBP: heparin-binding protein; Hep: heparin; Hep-2 cells: human epithelial type 2 cells; \\ HGF: hepatocyte growth factor; HS: heparan sulfate; IgG: Immunoglobulin G; IL-10: interleucine 10; IL-12: interleucine 12; iNOS: inducible nitric oxide synthase; IX: collagen 2; KS: keratan sulfate; LPG: lipophosphoglycan; MHC: major histocompatibility complex; MR: mannose receptor; NLR: nucleotide-binding oligomerization domain containing 2 (NOD2)-like receptor; NO: nitric oxide; PAMP: pathogen-associated molecular pattern; \\ PG: proteoglycans; $\mathrm{PGE}_{2}$ : prostaglandin $\mathrm{E}_{2}$; PRR: pattern recognition receptor; PS: phosphadidylserine; PSG: promastigote secretory gel; TGF- $\beta$ : transforming growth factor beta; TLR: toll-like receptor; TNF-a: tumor necrosis factor alpha; VEGF: vascular endothelial growth factor}

\section{Authors' contributions}

DAMB, SPC, CLRB and JLMW wrote the manuscript. DAMB produced the figures. All authors read and approved the final manuscript.

Ethics approval and consent to participate Not applicable.

Consent for publication

Not applicable.

Competing interests

The authors declare that they have no competing interests. 


\section{Publisher's Note}

Springer Nature remains neutral with regard to jurisdictional claims in published maps and institutional affiliations.

Received: 5 December 2017 Accepted: 13 June 2018

Published online: 03 October 2018

\section{References}

1. Reithinger R, Dujardin JC, Louzir H, Pirmez C, Alexander B, Brooker S. Cutaneous leishmaniasis. Lancet Infect Dis. 2007;7:581-96.

2. Ueno N, Wilson ME. Receptor-mediated phagocytosis of Leishmania: implications for intracellular survival. Trends Parasitol. 2012;28:335-44.

3. Gurung P, Kanneganti TD. Innate immunity against Leishmania infections. Cell Microbiol. 2015;17:1286-94.

4. Brittingham A, Morrison CJ, McMaster WR, McGwire BS, Chang KP, Mosser DM. Role of the Leishmania surface protease gp63 in complement fixation cell adhesion, and resistance to complement-mediated lysis. J Immunol. 1995;155:3102-11

5. Rosenthal LA, Sutterwala FS, Kehrli ME, Mosser DM. Leishmania majorhuman macrophage interactions: cooperation between Mac-1 (CD11b/ CD18) and complement receptor type 1 (CD35) in promastigote adhesion. Infect Immun. 1996:64:2206-15.

6. Brittingham A, Chen G, McGwire BS, Chang KP, Mosser DM. Interaction of Leishmania gp63 with cellular receptors for fibronectin. Infect Immun. 1999;67:4477-84.

7. Handman E, Goding JW. The Leishmania receptor for macrophages is a lipid-containing glycoconjugate. EMBO J. 1985;4:329-36.

8. Talamas-Rohana P, Wright SD, Lennartz MR, Russell DG. Lipophosphoglycan from Leishmania mexicana promastigotes binds to members of the CR3, p150,95 and LFA-1 family of leukocyte integrins. J Immunol. 1990;144:4817-24.

9. Guy RA, Belosevic M. Comparison of receptors required for entry of Leishmania major amastigotes into macrophages. Infect Immun. 1993; 61:1553-8.

10. Wanderley $\mathrm{L}$, Moreira ME, Benjamin A, Bonomo AC, Barcinski MA. Mimicry of apoptotic cells by exposing phosphatidylserine participates in the establishment of amastigotes of Leishmania (L.) amazonensis in mammalian hosts. J Immunol. 2006:176:1834-9.

11. Wanderley $J$, Pinto da Silva LH, Deolindo P, Soong L, Borges VM, Prates DB, et al. Cooperation between apoptotic and viable metacyclics enhances the pathogenesis of leishmaniasis. PLoS One. 2009;4:e5733.

12. Dos Santos JC, Damen M, Oosting M, de Jong DJ, Heinhuis B, Gomes RS, et al. The NOD2 receptor is crucial for immune responses towards New World Leishmania species. Sci Rep. 2017;7:15219.

13. Desjardins M, Descoteaux A. Inhibition of phagolysosomal biogenesis by the Leishmania lipophosphoglycan. J Exp Med. 1997;185:2061-8.

14. Lodge R, Descoteaux A. Modulation of phagolysosome biogenesis by the lipophosphoglycan of Leishmania. Clin Immunol. 2005;114:256-65.

15. Matheoud D, Moradin N, Bellemare-Pelletier A, Shio MT, Hong WJ, Olivier M, et al. Leishmania evades host immunity by inhibiting antigen crosspresentation through direct cleavage of the SNARE VAMP8. Cell Host Microbe. 2013;14:15-25.

16. Isnard A, Shio MT, Olivier M. Impact of Leishmania metalloprotease GP63 on macrophage signaling. Front Cell Infect Microbiol. 2012;2:72.

17. Panaro MA, Puccini V, Faliero SM, Marzio R, Marangi A, Lisi S, Brandonisio O. Leishmania donovani lipophosphoglycan (LPG) inhibits respiratory burst and chemotaxis of dog phagocytes. New Microbiol. 1996;19:107-12.

18. Balestieri FM, Queiroz AR, Scavone C, Costa VM, Barral-Netto M, Abrahamsohn Ide A. Leishmania (L.) amazonensis-induced inhibition of nitric oxide synthesis in host macrophages. Microbes Infect. 2002;4:23-9.

19. Zambrano-Villa S, Rosales-Borjas D, Carrero JC, Ortiz-Ortiz L. How protozoan parasites evade the immune response. Trends Parasitol. 2002;18:272-8.

20. De Souza Leao S, Lang T, Prina E, Hellio R, Antoine JC. Intracellular Leishmania amazonensis amastigotes internalize and degrade MHC class II molecules of their host cells. J Cell Sci. 1995;108:3219-31.

21. Giarola NL, Silveira TS, Inacio JD, Vieira LP, Almeida-Amaral EE, MeyerFernandes JR. Leishmania amazonensis: increase in ecto-ATPase activity and parasite burden of vinblastine-resistant protozoa. Exp Parasitol. 2014;146:25-33.

22. Peres-Sampaio CE, de Almeida-Amaral EE, Giarola NL, Meyer-Fernandes JR. Leishmania amazonensis: effects of heat shock on ecto-ATPase activity. Exp Parasitol. 2008;119:135-43.
23. Butcher BA, Shome K, Estes LW, Choay J, Petitou M, Sie P, Glew RH. Leishmania donovani: cell-surface heparin receptors of promastigotes are recruited from an internal pool after trypsinization. Exp Parasitol. 1990;71:49-59.

24. Butcher BA, Sklar LA, Seamer LC, Glew RH. Heparin enhances the interaction of infective Leishmania donovani promastigotes with mouse peritoneal macrophages. A fluorescence flow cytometric analysis. J Immunol. 1992;148:2879-86

25. Mukhopadhyay NK, Shome K, Saha AK, Hassell JR, Glew RH. Heparin binds to Leishmania donovani promastigotes and inhibits protein phosphorylation. Biochem J. 1989:264:517-25.

26. Nader HB, Chavante SF, dos-Santos EA, Oliveira TW, de-Paiva JF, Jeronimo SM, Medeiros GF, et al. Heparan sulfates and heparins: similar compounds performing the same functions in vertebrates and invertebrates? Braz J Med Biol Res. 1999:32:529-38.

27. Jackson RL, Busch SJ, Cardin AD. Glycosaminoglycans: molecular properties, protein interactions, and role in physiological processes. Physiol Rev. 1991;71:481-539.

28. Iozzo RV. Matrix proteoglycans: from molecular design to cellular function Annu Rev Biochem. 1998:67:609-52.

29. Lindahl U, Hook M. Glycosaminoglycans and their binding to biological macromolecules. Annu Rev Biochem. 1978;47:385-417.

30. Kjellen L, Lindahl U. Proteoglycans: structures and interactions. Annu Rev Biochem. 1991;60:443-75.

31. Kresse $\mathrm{H}$, Schonherr E. Proteoglycans of the extracellular matrix and growth control. J Cell Physiol. 2001;189:266-74.

32. Couchman JR, Pataki CA. An introduction to proteoglycans and their localization. J Histochem Cytochem. 2012;60:885-97.

33. Whitelock JM, lozzo RV. Isolation and purification of proteoglycans. Methods Cell Biol. 2002;69:53-67.

34. Salmivirta M, Lidholt K, Lindahl U. Heparan sulfate: a piece of information. FASEB J. 1996:10:1270-9.

35. Kusche-Gullberg M, Kjellén L. Sulfotransferases in glycosaminoglycan biosynthesis. Curr Opin Struct Biol. 2003;13:605-11.

36. Li JP, Kusche-Gullberg M. Heparan sulfate: biosynthesis, structure, and function. Int Rev Cell Mol Biol. 2016:325:215-73.

37. Prydz K. Determinants of glycosaminoglycan (GAG) structure. Biomolecules. 2015:5:2003-22.

38. Yurchenco PD, Schittny JC. Molecular architecture of basement membranes. FASEB J. 1990:4:1577-90.

39. Lord MS, Whitelock JM. Recombinant production of proteoglycans and their bioactive domains. FEBS J. 2013;280:2490-510.

40. David G, Lories V, Decock B, Marynen P, Cassiman JJ, Van den Berghe $\mathrm{H}$. Molecular cloning of a phosphatidylinositol-anchored membrane heparan sulfate proteoglycan from human lung fibroblasts. J Cell Biol. 1990;111:3165-76.

41. Kjellen L, Pettersson I, Hook M. Cell-surface heparan sulfate: an intercalated membrane proteoglycan. Proc Natl Acad Sci USA. 1981;78:5371-5.

42. Gandhi NS, Mancera RL. The structure of glycosaminoglycans and their interactions with proteins. Chem Biol Drug Des. 2008;72:455-82.

43. Saunders $\mathrm{S}$, Bernfield M. Cell surface proteoglycan binds mouse mammary epithelial cells to fibronectin and behaves as a receptor for interstitial matrix. J Cell Biol. 1988:106:423-30.

44. Elenius K, Salmivirta M, Inki P, Mali M, Jalkanen M. Binding of human syndecan to extracellular matrix proteins. J Biol Chem. 1990:265:17837-43.

45. Faham S, Linhardt RJ, Rees DC. Diversity does make a difference: fibroblast growth factor-heparin interactions. Curr Opin Struct Biol. 1998:8:578-86.

46. Mitsiadis TA, Salmivirta M, Muramatsu T, Muramatsu $H$, Rauvala $H$, Lehtonen $E$, et al. Expression of the heparin-binding cytokines, midkine (MK) and HB-GAM (pleiotrophin) is associated with epithelial-mesenchymal interactions during fetal development and organogenesis. Development. 1995;121:37-51.

47. San Antonio JD, Karnovsky MJ, Gay S, Sanderson RD, Lander AD. Interactions of syndecan-1 and heparin with human collagens. Glycobiology. 1994:4:327-32.

48. Lopez-Casillas F, Payne HM, Andres JL, Massague J. Betaglycan can act as a dual modulator of TGF-beta access to signaling receptors: mapping of ligand binding and GAG attachment sites. J Cell Biol. 1994;124:557-68.

49. Prehm P. Synthesis of hyaluronate in differentiated teratocarcinoma cells. Mechanism of chain growth. Biochem J. 1983;211:191-8.

50. Almeida PC, Nantes IL, Chagas JR, Rizzi CC, Faljoni-Alario A, Carmona E, et al. Cathepsin $\mathrm{B}$ activity regulation. Heparin-like glycosaminogylcans protect 
human cathepsin B from alkaline pH-induced inactivation. J Biol Chem. 2001;276:944-51.

51. Borsig L, Wang L, Cavalcante MC, Cardilo-Reis L, Ferreira PL, Mourão PA, et al. Selectin blocking activity of a fucosylated chondroitin sulfate glycosaminoglycan from sea cucumber. Effect on tumor metastasis and neutrophil recruitment. J Biol Chem. 2007;282:14984-91.

52. Angeletti D, Sandalova T, Wahlgren M, Achour A. Binding of subdomains 1/ 2 of PfEMP1-DBL1a to heparan sulfate or heparin mediates Plasmodium falciparum rosetting. PLoS One. 2015;5:e0118898.

53. McLean J. The thromboplastic action of cephalin. Am J Phys. 1916;41:250-7.

54. Thakar D, Dalonneau F, Migliorini E, Lortat-Jacob H, Boturyn D, Albiges-Rizo $C$, et al. Binding of the chemokine CXCL12a to its natural extracellular matrix ligand heparan sulfate enables myoblast adhesion and facilitates cell motility. Biomaterials. 2017;123:24-38.

55. Takemae H, Kobayashi K, Sugi T, Han Y, Gong H, Ishiwa A, et al. Toxoplasma gondii RON4 binds to heparan sulfate on the host cell surface. Parasitol Int. 2018;67:123-30.

56. Ndonwi M, Burlingame OO, Miller AS, Tollefsen DM, Broze GJ Jr, Goldberg DE. Inhibition of antithrombin by Plasmodium falciparum histidine-rich protein II. Blood. 2011;117:6347-54.

57. Shworak NW, Shirakawa M, Colliec-Jouault S, Liu J, Mulligan RC, Birinyi LK, Rosenberg RD. Pathway-specific regulation of the synthesis of anticoagulantly active heparan sulfate. J Biol Chem. 1994;269:24941-52.

58. Milstone LM, Hough-Monroe L, Kugelman LC, Bender JR, Haggerty JG. Epican, a heparan/chondroitin sulfate proteoglycan form of CD44, mediates cell-cell adhesion. J Cell Sci. 1994;107:3183-90.

59. Rogerson SJ, Chaiyaroj SC, Ng K, Reeder JC, Brown GV. Chondroitin sulfate A is a cell surface receptor for Plasmodium falciparum-infected erythrocytes. J Exp Med. 1995;182:15-20.

60. Ayres Pereira M, Mandel Clausen T, Pehrson C, Mao Y, Resende M, Daugaard $M$, et al. Placental sequestration of Plasmodium falciparum malaria parasites is mediated by the interaction between VAR2CSA and chondroitin sulfate A on syndecan-1. PLoS Pathog. 2016;12:e1005831.

61. Mourão PA, Pereira MS, Pavão MS, Mulloy B, Tollefsen DM, Mowinckel MC, Abildgaard U. Structure and anticoagulant activity of a fucosylated chondroitin sulfate from echinoderm. Sulfated fucose branches on the polysaccharide account for its high anticoagulant action. J Biol Chem. 1996;271:23973-84.

62. Glauser BF, Pereira MS, Monteiro RQ, Mourão PA. Serpin-independent anticoagulant activity of a fucosylated chondroitin sulfate. Thromb Haemost. 2008;100:420-8.

63. Lewandowska K, Choi HU, Rosenberg LC, Sasse J, Neame PJ, Culp LA. Extracellular matrix adhesion-promoting activities of a dermatan sulfate proteoglycan-associated protein (22K) from bovine fetal skin. J Cell Sci. 1991;99:657-68.

64. Nadafi R, Koning JJ, Veninga H, Stachtea XN, Konijn T, Zwiers A, et al. Dendritic cell migration to skin-draining lymph nodes is controlled by dermatan sulfate and determines adaptive immunity magnitude. Front Immunol. 2018;9:206.

65. Fortune DE, Lin YP, Deka RK, Groshong AM, Moore BP, Hagman KE, et al. Identification of lysine residues in the Borrelia burgdorferi DbpA adhesin required for murine infection. Infect Immun. 2014;82:3186-98.

66. Ofosu FA, Modi GJ, Smith LM, Cerskus AL, Hirsh J, Blajchman MA. Heparan sulfate and dermatan sulfate inhibit the generation of thrombin activity in plasma by complementary pathways. Blood. 1984;64:742-7.

67. Underhill C, Dorfman A. The role of hyaluronic acid in intercellular adhesion of cultured mouse cells. Exp Cell Res. 1978;117:155-64.

68. Horton MR, Shapiro S, Bao C, Lowenstein CJ, Noble PW. Induction and regulation of macrophage metalloelastase by hyaluronan fragments in mouse macrophages. J Immunol. 1999;162:4171-6.

69. Termeer CC, Hennies J, Voith U, Ahrens T, Weiss JM, Prehm P, Simon JC. Oligosaccharides of hyaluronan are potent activators of dendritic cells. J Immunol. 2000;165:1863-70.

70. Beeson JG, Rogerson SJ, Cooke BM, Reeder JC, Chai W, Lawson AM, et al. Adhesion of Plasmodium falciparum-infected erythrocytes to hyaluronic acid in placental malaria. Nat Med. 2000;6:86-90.

71. Skinsnes OK, Matsuo E. Acid mucopolysaccharide metabolism in leprosy. 1. Storage of hyaluronic acid and its possible significance in the pathogenesis of leprosy. Int J Lepr Other Mycobact Dis. 1974;42:392-8.

72. Funderburgh JL, Funderburgh ML, Mann MM, Prakash S, Conrad GW. Synthesis of corneal keratan sulfate proteoglycans by bovine keratocytes in vitro. J Biol Chem. 1996;271:31431-6.
73. Leroux JY, Guerassimov A, Cartman A, Delaunay N, Webber C, Rosenberg LC, et al. Immunity to the G1 globular domain of the cartilage proteoglycan aggrecan can induce inflammatory erosive polyarthritis and spondylitis in BALB/c mice but immunity to $\mathrm{G} 1$ is inhibited by covalently bound keratan sulfate in vitro and in vivo. J Clin Invest. 1996;97:621-32.

74. Naor D, Sionov RV, Ish-Shalom D. CD44: structure, function, and association with the malignant process. Adv Cancer Res. 1997;71:241-319.

75. Mikami T, Kitagawa H. Biosynthesis and function of chondroitin sulfate. Biochim Biophys Acta. 2013;1830:4719-33.

76. Yamaguchi H. Studies on the carbohydrate-protein linkage region in bovine corneal keratan sulfate II. Structural studies on linkage region-enriched neutral glycopeptides. J Biochem. 1983;94:215-21.

77. Pavão MS. Glycosaminoglycans analogs from marine invertebrates: structure, biological effects, and potential as new therapeutics. Front Cell Infect Microbiol. 2014;4:123.

78. Lidholt K, Kjellen L, Lindahl U. Biosynthesis of heparin. Relationship between the polymerization and sulphation processes. Biochem J. 1989;261:999-1007.

79. Piepkorn M, Hovingh P, Linker A. Glycosaminoglycan free chains. External plasma membrane components distinct from the membrane proteoglycans. J Biol Chem. 1989;264:8662-9.

80. Sasisekharan R, Raman R, Prabhakar V. Glycomics approach to structure-function relationships of glycosaminoglycans. Annu Rev Biomed Eng. 2006;8:181-231.

81. Sarrazin S, Lamanna WC, Esko JD. Heparan sulfate proteoglycans. Cold Spring Harb Perspect Biol. 2011;3:a4952.

82. van Kooyk Y, Rabinovich GA. Protein-glycan interactions in the control of innate and adaptive immune responses. Nat Immunol. 2008;9:593-601.

83. Afratis NA, Nikitovic D, Multhaupt HA, Theocharis AD, Couchman JR, Karamanos NK. Syndecans - key regulators of cell signaling and biological functions. FEBS J. 2017;284:27-41.

84. Bishop JR, Schuksz M, Esko JD. Heparan sulfate proteoglycans fine-tune mammalian physiology. Nature. 2007:446:1030-7.

85. Chen Y, Gotte M, Liu J, Park PW. Microbial subversion of heparan sulfate proteoglycans. Mol Cell. 2008;26:415-26.

86. Aquino RS, Park PW. Glycosaminoglycans and infection. Front Biosci (Landmark Ed). 2016;21:1260-77.

87. Bernfield M, Gotte M, Park PW, Reizes O, Fitzgerald ML, Lincecum J, Zako M. Functions of cell surface heparan sulfate proteoglycans. Annu Rev Biochem. 1999;68:729-77.

88. Parish CR. The role of heparan sulfate in inflammation. Nat Rev Immunol. 2006;6:633-43.

89. Belmiro CL, Castelo-Branco MT, Melim LM, Schanaider A, Elia C, Madi K, et al. Unfractionated heparin and new heparin analogues from ascidians (chordatetunicate) ameliorate colitis in rats. J Biol Chem. 2009;284:11267-78.

90. Pejler G, Danielsson A, Bjork I, Lindahl U, Nader HB, Dietrich CP. Structure and antithrombin-binding properties of heparin isolated from the clams Anomalocardia brasiliana and Tivela mactroides. J Biol Chem. 1987;262:11413-21.

91. Gomes AM, Kozlowski EO, Pomin VH, de Barros CM, Zaganeli JL, Pavao MS. Unique extracellular matrix heparan sulfate from the bivalve Nodipecten nodosus (Linnaeus, 1758) safely inhibits arterial thrombosis after photochemically induced endothelial lesion. J Biol Chem. 2010;285:7312-23.

92. Hikino M, Mikami T, Faissner A, Vilela-Silva AC, Pavao MS, Sugahara K. Oversulfated dermatan sulfate exhibits neurite outgrowth-promoting activity toward embryonic mouse hippocampal neurons: implications of dermatan sulfate in neuritogenesis in the brain. J Biol Chem. 2003;278:43744-54.

93. Bao X, Pavao MS, Dos Santos JC, Sugahara K. A functional dermatan sulfate epitope containing iduronate(2-O-sulfate)alpha1-3GalNAc(6-O-sulfate) disaccharide in the mouse brain: demonstration using a novel monoclonal antibody raised against dermatan sulfate of ascidian Ascidia nigra. J Biol Chem. 2005;280:23184-93.

94. Fonseca RJ, Mourao PA. Fucosylated chondroitin sulfate as a new oral antithrombotic agent. Thromb Haemost. 2006;96:822-9.

95. Stevenson JL, Varki A, Borsig L. Heparin attenuates metastasis mainly due to inhibition of $\mathrm{P}$ - and L-selectin, but non-anticoagulant heparins can have additional effects. Thromb Res. 2007:120(Suppl. 2):S107-11.

96. Hwang S, Greenlee JJ, Nicholson EM. Use of bovine recombinant prion protein and real-time quaking-induced conversion to detect cattle transmissible mink encephalopathy prions and discriminate classical and atypical L- and H-Type bovine spongiform encephalopathy. PLoS One. 2017;12:e0172391. 
97. Sacks DL. Metacyclogenesis in Leishmania promastigotes. Exp Parasitol. 1989:69:100-3.

98. Bates PA. Transmission of Leishmania metacyclic promastigotes by phlebotomine sand flies. Int J Parasitol. 2007;37:1097-106.

99. Stierhof YD, llg T, Russell DG, Hohenberg H, Overath P. Characterization of polymer release from the flagellar pocket of Leishmania mexicana promastigotes. J Cell Biol. 1994;125:321-31.

100. Rogers ME. The role of Leishmania proteophosphoglycans in sand fly transmission and infection of the Mammalian host. Front Microbiol. 2012;3:223.

101. Rogers ME, Corware K, Muller I, Bates PA. Leishmania infantum proteophosphoglycans regurgitated by the bite of its natural sand fly vector, Lutzomyia longipalpis, promote parasite establishment in mouse skin and skin-distant tissues. Microbes Infect. 2010;12:875-9.

102. Foth B, Piani A, Curtis JM, Ilg T, McConville M, Handman E. Leishmania major proteophosphoglycans exist as membrane-bound and soluble forms and localise to the cell membrane, the flagellar pocket and the lysosome. Int J Parasitol. 2002;32:1701-8.

103. Rogers M, Kropf P, Choi BS, Dillon R, Podinovskaia M, Bates P, Muller I. Proteophosophoglycans regurgitated by Leishmania-infected sand flies target the L-arginine metabolism of host macrophages to promote parasite survival. PLoS Pathog. 2009;5:e1000555.

104. McConville MJ, Homans SW, Thomas-Oates JE, Dell A, Bacic A. Structures of the glycoinositolphospholipids from Leishmania major. A family of novel galactofuranose-containing glycolipids. J Biol Chem. 1990;265:7385-94.

105. McConville MJ, Ferguson MA. The structure, biosynthesis and function of glycosylated phosphatidylinositols in the parasitic protozoa and higher eukaryotes. Biochem J. 1993;294:305-24.

106. McConville MJ, Blackwell JM. Developmental changes in the glycosylated phosphatidylinositols of Leishmania donovani. Characterization of the promastigote and amastigote glycolipids. J Biol Chem. 1991;266:15170-9.

107. McConville MJ, Collidge TA, Ferguson MA, Schneider P. The glycoinositol phospholipids of Leishmania mexicana promastigotes. Evidence for the presence of three distinct pathways of glycolipid biosynthesis. J Biol Chem. 1993;268:15595-604.

108. Zawadzki J, Scholz C, Currie G, Coombs GH, McConville MJ. The glycoinositolphospholipids from Leishmania panamensis contain unusual glycan and lipid moieties. J Mol Biol. 1998;282:287-99.

109. McConville MJ. Bacic A. A family of glycoinositol phospholipids from Leishmania major. Isolation, characterization, and antigenicity. J Biol Chem. 1989;264:757-66.

110. Iniguez E, Schocker NS, Subramaniam K, Portillo S, Montoya AL, Al-Salem WS, et al. An a-Gal-containing neoglycoprotein-based vaccine partially protects against murine cutaneous leishmaniasis caused by Leishmania major. PLoS Negl Trop Dis. 2017;11:e0006039.

111. Assis RR, Ibraim IC, Noronha FS, Turco SJ, Soares RP. Glycoinositolphospholipids from Leishmania braziliensis and L. infantum: modulation of innate immune system and variations in carbohydrate structure. PLoS Negl Trop Dis. 2012;6:e1543.

112. McGwire BS, Chang KP, Engman DM. Migration through the extracellular matrix by the parasitic protozoan Leishmania is enhanced by surface metalloprotease gp63. Infect Immun. 2003;71:1008-10.

113. Fatoux-Ardore M, Peysselon F, Weiss A, Bastien P, Pratlong F, RicardBlum S. Large-scale investigation of Leishmania interaction networks with host extracellular matrix by surface plasmon resonance imaging. Infect Immun. 2014;82:594-606.

114. Silva-Almeida M, Carvalho LO, Abreu-Silva AL, Souza CS, Hardoim DJ, Calabrese KS. Extracellular matrix alterations in experimental Leishmania amazonensis infection in susceptible and resistant mice. Vet Res. 2012;43:10.

115. Naderer T, Heng J, Saunders EC, Kloehn J, Rupasinghe TW, Brown TJ, McConville MJ. Intracellular survival of Leishmania major depends on uptake and degradation of extracellular matrix glycosaminoglycans by macrophages. PLoS Pathog. 2015;11:e1005136.

116. Seneca $H$, Henderson $E$, Harvey M. Effect of hyaluronidase and of hyaluronic acid on cultures of trypanosomes, Leishmania, and Amoebae. Science. 1948;108:714-5.

117. Almeida PC, Nantes IL, Rizzi CC, Judice WA, Chagas JR, Juliano L, et al. Cysteine proteinase activity regulation. A possible role of heparin and heparin-like glycosaminoglycans. J Biol Chem. 1999;274:30433-8.

118. Motta G, Tersariol ILS. Modulation of the plasma kallikrein-kinin system proteins performed by heparan sulfate proteoglycans. Front Physiol. 2017;8:481-8.
119. Lima AP, Almeida PC, Tersariol IL, Schmitz V, Schmaier AH, Juliano L, et al. Heparan sulfate modulates kinin release by Trypanosoma cruzi through the activity of cruzipain. J Biol Chem. 2002;277:5875-81.

120. Li Z, Hou WS, Bromme D. Collagenolytic activity of cathepsin K is specifically modulated by cartilage-resident chondroitin sulfates. Biochemistry. 2000;39:529-36.

121. Judice WA, Manfredi MA, Souza GP, Sansevero TM, Almeida PC, Shida CS, et al. Heparin modulates the endopeptidase activity of Leishmania mexicana cysteine protease cathepsin L-Like rCPB2.8. PLoS One. 2013;8:e80153.

122. Martins TV, de Carvalho TV, de Oliveira CV, de Paula SO, Cardoso SA, de Oliveira LL, Marques-da-Silva Ede A. Leishmania chagasi heparin-binding protein: cell localization and participation in L. chagasi infection. Mol Biochem Parasitol. 2015;204:34-43.

123. Azevedo-Pereira RL, Pereira MC, Oliveria-Junior FO, Brazil RP, Cortes LM, Madeira MF, et al. Heparin-binding proteins from Leishmania (Viannia) braziliensis promastigotes. Vet Parasitol. 2007;145:234-9.

124. de Castro Cortes LM, de Souza Pereira MC, de Oliveira FO Jr, Corte-Real S, da Silva FS, Pereira BA, et al. Leishmania (Viannia) braziliensis: insights on subcellular distribution and biochemical properties of heparin-binding proteins. Parasitology. 2012;139:200-7.

125. Love DC, Esko JD, Mosser DM. A heparin-binding activity on Leishmania amastigotes which mediates adhesion to cellular proteoglycans. J Cell Biol. 1993;123:759-66.

126. de Castro Cortes LM, de Souza Pereira MC, da Silva FS, Pereira BA, de Oliveira Junior FO, de Araujo Soares RO, et al. Participation of heparinbinding proteins from the surface of Leishmania (Viannia) braziliensis promastigotes in the adhesion of parasites to Lutzomyia longipalpis cells (Lulo) in vitro. Parasit Vectors. 2012;5:142.

127. Oliveira FO Jr, Alves CR, Calvet CM, Toma L, Boucas RI, et al. Trypanosoma cruzi heparin-binding proteins and the nature of the host cell heparan sulfate-binding domain. Microb Pathog. 2008;44:329-38.

128. Bambino-Medeiros R, Oliveira FO, Calvet CM, Vicente D, Toma L, Krieger MA, et al. Involvement of host cell heparan sulfate proteoglycan in Trypanosoma cruzi amastigote attachment and invasion. Parasitology. 2011;138:593-601.

129. Alvarenga V Jr, Pacheco RG, Esposito CC, Buongusto F, Castelo-Branco MT, Madi K, et al. Ascidian (chordate-tunicate) and mammalian heparin enemas attenuate experimental diversion colitis. Surgery. 2014;155:217-27.

\section{Ready to submit your research? Choose BMC and benefit from:}

- fast, convenient online submission

- thorough peer review by experienced researchers in your field

- rapid publication on acceptance

- support for research data, including large and complex data types

- gold Open Access which fosters wider collaboration and increased citations

- maximum visibility for your research: over $100 \mathrm{M}$ website views per year

At BMC, research is always in progress.

Learn more biomedcentral.com/submissions 